\title{
Repeated Doses of Ketamine Affect the Infant Rat Urogenital System
}

This article was published in the following Dove Press journal:

Drug Design, Development and Therapy

\author{
Hulya Kasıkara' \\ Nuran Sungu ${ }^{2}$ \\ Mustafa Arslan (iD ${ }^{3}$ \\ Aysegul Kucuk (D) ${ }^{4}$ \\ Levent Ozturk (1D ${ }^{5}$ \\ Nigar Afandiyeva ${ }^{6}$ \\ Mustafa Kavutcu ${ }^{6}$ \\ 'Department of Anaesthesiology and \\ Reanimation, Ankara City Hospital, \\ Ankara, Turkey; ${ }^{2}$ Medical Faculty, \\ Department of Pathology, Yıldırım \\ Bayazit University, Ankara, Turkey; \\ ${ }^{3}$ Medical Faculty, Department of \\ Anaesthesiology and Reanimation, Gazi \\ University, Ankara, Turkey; ${ }^{4}$ Medical \\ Faculty, Department of Physiology, \\ Kutahya Health Sciences University, \\ Kutahya, Turkey; ${ }^{5}$ Medical Faculty, \\ Department of Anaesthesiology and \\ Reanimation, Yıldırım Bayazit University, \\ Ankara, Turkey; ${ }^{6}$ Medical Faculty, \\ Department of Biochemistry, Gazi \\ University, Ankara, Turkey
}

Aim: Long-term ketamine use is known to create an interstitial cystitis-like problem in the bladder. It is known that long-term intermittent ketamine is applied to the children receiving radiotherapy for sedation. This study was planned to investigate whether this effect seen in the bladder causes similar changes in the kidneys, testicles, epididymis and ductus deferens. Materials and Methods: A total of 12 male Wistar Albino rats for 3 weeks were used in the study. Rats were divided equally into 2 groups as, ketamine and saline. $50 \mathrm{mg} / \mathrm{kg}$ ketamine was administered intraperitoneally during 21 days to ketamine $(\mathrm{K})$ groups. $1 \mathrm{~mL} /$ $\mathrm{kg}$ saline was administered intraperitoneally during 21 days to saline $(\mathrm{S})$ groups. At the end of 21 days kidney and testicular tissues were taken for biochemical and histopathological evaluations.

Results: Histological assessment of kidney tissue showed that tubule epithelial congestion increased significantly in the ketamine group. Epididymis congestion and distortion in the epididymal gland were found to be different in the ketamine group when testicular tissue was examined. Thiobarbituric acid reactive substances (TBARS) level in testicular and kidney tissue was found to be significantly higher in the ketamine group according to the saline group. Catalase (CAT) enzyme activity was significantly lower in the ketamine group compared to the saline group in both tissues. Paraoxonase-1 (PON-1) enzyme activity was significantly higher in the ketamine group compared to the saline group.

Conclusion: We think that the results we have achieved in this study will provide guidance on ketamine, which is repeated in daily anesthesia applications, especially in radiation oncology. But these findings should be supported by clinical and experimental studies that will be conducted in a more detailed and broad series.

Keywords: ketamine, infant rat, testicular tissue, kidney, epididymis

\section{Introduction}

Ketamine is an N-methyl-D-aspartic acid receptor antagonist and provides loss of consciousness, amnesia, immobility and deep analgesia in anesthesia. ${ }^{1}$ Ketamine was first synthesized in 1962 and introduced into clinical medicine for dissociative anesthesia in $1970 .^{2}$ It is used as a short-acting general anesthetic in human and veterinary clinics. As a non-respiratory and non-cardiac depressant, anesthetic doses of ketamine are preferred over other anesthetics. ${ }^{3}$ Because of this feature, ketamine has been widely used alone in premedication, sedation and postoperative analgesia or combined with a reduced dose of a second analgesic for many years, especially in the pediatric age group. ${ }^{4-6}$ Ketamine is even recommended for the treatment of status asthmaticus in children due to its bronchodilator properties. ${ }^{7}$ Ketamine is the most preferred agent, especially in children who receive radiotherapy for a certain period
Correspondence: Mustafa Arslan Medical Faculty, Department of Anesthesiology and Reanimation, Gazi University, Ankara, 06510, Turkey Tel +90 3I2 2026739

Email mustarslan@gmail.com 
of time due to cancer diagnosis or in children who require intermittent sedation for daily dressing in the burn unit. At subanesthetic doses, ketamine produces a dissociative state, characterized by a sense of detachment from one's physical body and the external world which is known as depersonalization and derealization. ${ }^{8}$ Due to its hallucinogenic effect, abuse and addiction are also very common in Far Eastern countries such as Hong Kong, Taiwan and in Europe in recent years. ${ }^{9,10}$ Long-term ketamine use in adults is known to create a interstitial cystitis-like problem in the bladder. It has been called ketamine cystitis due to its prevalence in ketamine addicts. Characteristic cystoscopic findings and histological changes in bladder biopsies of these patients; a thinner urothelium, mast cell infiltration, tissue inflammation, and fibrosis. Tissue inflammation and fibrosis, an indicator of ketamine-induced cystitis in adults, has been shown in animal studies. ${ }^{11,12}$ In recent animal studies, it has been shown that widespread apoptotic neurodegeneration occurs in the developing baby rat brain after exposure to ketamine for a certain period of time. ${ }^{13}$ Various deleterious effects of chronic ketamine intake has been reported, including apoptotic neurodegeneration in the brain, reduction in gray matter, intracranial hypertension, and neuropsychiatric symptoms. Antioxidant systems normally work in integrity, protecting the cell against the toxic effects of free oxygen radicals. They do this by keeping the oxidant and antioxidant systems in the organism in balance. In cases where this balance is disrupted in favor of oxidant capacity, inflammatory mediators and free oxygen radicals are produced. ${ }^{14,15}$ Free radicals can contribute to organism disorders by targeting biomolecules of cells such as lipids, carbohydrates, proteins and DNA. Many reasons can lead to the formation of free oxygen radicals in the organism. Animal studies show that long-term administration of ketamine cause lipid peroxidation in the testicles. It has been demonstrated by several mechanisms that increased reactive oxygen species (ROS) negatively affect testicular functions. ROS attacks the sperm plasma membrane and causes lipid peroxidation. Additionally, ROS causes DNA fragmentation and decreases sperm motility. ${ }^{16,17}$ In a recent animal study, malondialdehyde MDA level was examined in order to investigate the effect of repeated ketamine treatment on the testis. According to the results, it has been reported that repetitive ketamine treatment may have dangerous effects on reproductive function. ${ }^{18}$ MDA has been used for many years as a suitable biomarker for lipid peroxidation of fatty acids in the cell membrane due to its easy reaction with thiobarbituric acid. The thiobarbituric acid test is based on the reactivity of thiobarbituric acid to MDA to obtain an intensely colored chromogen fluorescent color absorbent. CAT enzyme is used as a biomarker to measure antioxidant capacity. CAT is a hemoprotein that contains a single ferriprotoporphyrin in each polypeptide subunit structure. It constantly monitors hydrogen peroxide $\left(\mathrm{H}_{2} \mathrm{O}_{2}\right)$ molecules, as a lipid peroxidation product. CAT can break down millions of $\mathrm{H}_{2} \mathrm{O}_{2}$ molecules in one second. It is important that CAT can effectively limit the $\mathrm{H}_{2} \mathrm{O}_{2}$ concentration in cells and plays a role as a first-step antioxidant defense enzyme in physiological processes. ${ }^{19}$ Studies on testicular tissue has shown that free oxygen radicals cause ischemia reperfusion damage. ${ }^{20,21}$ In addition, various studies have been reported on the disruption of the seminiferous epithelium and the loss of germ cells. ${ }^{22}$

Long-term ketamine use is known to create an interstitial cystitis-like problem in the bladder. It is known that long-term intermittent ketamine is applied to the children receiving radiotherapy for sedation. This study was planned to investigate whether this effect seen in the bladder causes similar changes in the kidneys, testicles, epididymis and ductus deferens.

\section{Materials and Methods}

This study was conducted in accordance with the guidelines of the National Institutes of Health on animal research and it was approved by the Animal Experiments Local Ethics Committee of Gazi University (G. U. ET18.092). 3 weeks old 12 Wistar Albino male infant rats were used in the study. All animals were kept in the Animal Care Laboratory of Gazi University. Animals were kept under $21 \pm 22{ }^{\circ} \mathrm{C}$ at cycles of 12-hour day light and 12-hour darkness and had free access to food and water. A total of 12 rats were equally randomized into 2 groups as; ketamine (K) and saline (S) group. $50 \mathrm{mg} / \mathrm{kg}$ of ketamine was administered intraperitoneally (i.p) to the ketamine group and $1 \mathrm{~mL} / \mathrm{kg}$ (i.p) saline was administered to the saline group during 21 days. For euthanasia, 100 $\mathrm{mg} / \mathrm{kg}$ of ketamine (i.p) and $10 \mathrm{mg} / \mathrm{kg}$ of xylazine (i.p) were administered to all rats and blood was taken from the abdominal aorta. Kidney, epididymis and testicular tissues were removed for and histopathological and biochemical evaluations.

\section{Histopathological Evaluations}

Kidney, epididymis and testicular tissue samples were taken in the formalin solution for histopathological analysis. After 12 hours of formol fixation, tissues were 
embedded in paraffin blocks. Sections obtained from paraffin blocks were stained with Hemotoxylin eosin (H\&E). The presence of tubular epithelial degeneration, tubular epithelial edema, vascular congestion, tubule dilation, interstitial edema, interstitial fibrosis, interstitial inflammation, glomerular sclerosis, bowman capsule fibrosis, and tubular atrophy was evaluated in H\&E sections. Seminiferous tubule dilatation, stromal fibrosis, epididymal congestion, distortion in the epididymal gland and ductus deferens were evaluated in testis and epididymis tissues. Testicular tissue sections were scanned on the Aperio AT2 device and then seminiferous tubules were marked from each section. Short diameters of the marked tubules were calculated with the metric measurement option after 100 tubule annotations were made on digital slides with Virapath application. Occlusion presence was evaluated at 40 magnification and other parameters at 200 magnification.

\section{Histological Evaluation and Maturation of Seminiferous Tubules}

The Johnsen score was used to evaluate spermatogenesis in the seminiferous tubules (Figure 1). 50 seminiferous tubules were examined in cross-section and a score of
1-10 was assigned to each of them according to the following criteria. $^{23} 10$ : complete spermatogenesis and perfect tubules, 9: many spermatozoa present but disorganized spermatogenesis, 8: only a few spermatozoa present, 7: no spermatozoa but many spermatids present, 6: only a few spermatids present, 5: no spermatozoa or spermatids present but many spermatocytes present, 4: only a few spermatocytes present, 3: only spermatogonia present, 2: no germ cells present, 1: neither germ cells nor sertoli cells present Each score score was multiplied by the number of tubules seen. The results were summed and divided by the number of 50 tubules and the average score was found. In addition, two groups were evaluated according to the presence of spermatozoa. Group 1: scores with spermatozoa between 8-10, Group 2: scores without spermatozoa between 1-7.

\section{Biochemical Evaluations}

The kidney and testicular tissues were washed with cold $\mathrm{NaCl}$ solution $(0.154 \mathrm{M})$ to discard blood contamination and then homogenized in a Diax 900; Heidolph Instruments $\mathrm{GmbH} \& \mathrm{Co} \mathrm{KG}$, Schwabach, Germany at $1000 \mathrm{U}$ for about $3 \mathrm{~min}$. After centrifugation at 10,000 g for about $60 \mathrm{~min}$, the upper clear layer was taken.

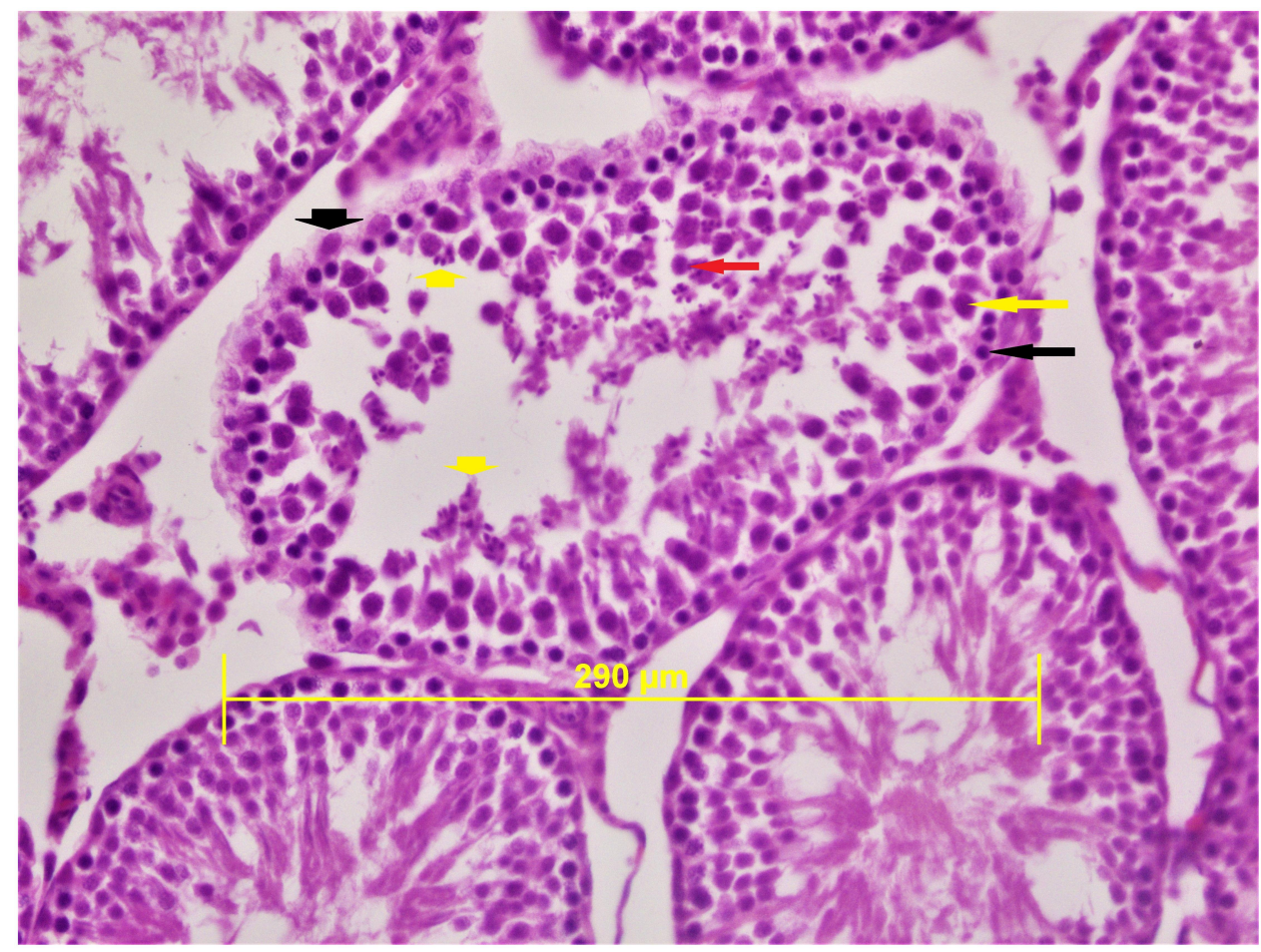

Figure I The spermatogenesis and spermiogenesis processes are normal and seminiferous tubules with a high proportion of spermatozoa are observed. Spermatogoniablack long arrow, sertoli cell: black short arrow, spermatocyte: yellow long arrow, spermatozoa: yellow short arrows, spermatitis: red arrow (H\&E×400). 
MDA levels, thiobarbituric acid reactive substances assay was performed by Van Ye method. ${ }^{7}$ The reaction with thiobarbituric acid at $90-100^{\circ} \mathrm{C}$ was used to determine the MDA level, as MDA or similar substances react with thiobarbituric acid and produce a pink pigment that has an absorption maximum of $532 \mathrm{~nm}$. To ensure protein precipitation, the sample in room temperature is mixed with cold $20 \%(\mathrm{w} / \mathrm{v})$ trichloroacetic acid and the precipitate is then centrifuged for $10 \mathrm{~min} 3000 \mathrm{rpm}$ at room temperature to form a pellet. An aliquot of the supernatant is then placed into an equal volume of $0.6 \%(\mathrm{wt} / \mathrm{vol})$ thiobarbituric acid in a boiling water bath for $30 \mathrm{~min}$. Following cooling, sample and blank absorbance were read at $532 \mathrm{~nm}$ and the results expressed as nmol/mg protein, based on a graph where 1,1,3,3-tetramethoxypropane has been used as the our MDA standard.

CAT activity is based on the measurement of absorbance decrease due to $\mathrm{H}_{2} \mathrm{O}_{2}$ consumption at $240 \mathrm{~nm}$ by Aebi $\mathrm{H}$ method. ${ }^{8}$ PON-1 activity was measured the rate of hydrolysis of paraoxon by monitoring the increase of absorbance at $405 \mathrm{~nm}$ and at $25{ }^{\circ} \mathrm{C}$. The basal assay mixture included $1.0 \mathrm{mM}$ paraoxon and $1.0 \mathrm{mM} \mathrm{CaCl} 2$ in Tris/ $\mathrm{HCl}$ buffer (pH: 8.0, $100 \mathrm{mM}$ ). The definition of 1 unit of paraoxonase activity was taken as 1 millimole of p-nitrophenol formed per minute. ${ }^{9}$

CAT and PON-1 activities were given in IU/mg protein. Samples protein amount was determined by Lowry $\mathrm{O}$ method, BSA was used standard protein. ${ }^{10}$

\section{Statistical Analysis}

All the data analyses were performed using SPSS 20.0 software (SPSS Inc., Chicago, IL). Data are presented as means \pm SEM. Histopathological data of rat kidney tissue, testicular tubule and CAT, PON-1 enzyme activities and TBARS level of rat kidney and testicular tissues the groups were analyzed using students $t$ test. Histopathological data of rat testicular tissue between the groups were analyzed with Fisher's test and $\chi^{2}$ test. $\mathrm{P}<0.05$ was considered significant.

\section{Results}

\section{Histopathological Results}

In testicular tissue, congestion and distortion in the epididymal gland were found to be different in the ketamine group compared to the saline group $(\mathrm{p}=0.015, \mathrm{p}=0.015$, respectively) (Table 1). Testicular tubule diameter increased significantly in the ketamine group compared with the saline
Table I Histopathological Data of Rat Testicular Tissue [N\%]

\begin{tabular}{|c|c|c|c|}
\hline & $\begin{array}{c}\text { Group S } \\
(n=6) \\
\text { (Absent/ } \\
\text { Present) }\end{array}$ & $\begin{array}{c}\text { Group K } \\
(n=6) \\
\text { (Absent/ } \\
\text { Present) }\end{array}$ & $\mathbf{P}$ \\
\hline $\begin{array}{l}\text { Seminiferous } \\
\text { tubule dilatation }\end{array}$ & $6(100) / 0(0)$ & $6(100) / 0(0)$ & - \\
\hline Stromal fibrosis & $6(100) / 0(0)$ & $6(100) / 0(0)$ & - \\
\hline $\begin{array}{l}\text { Epididymal } \\
\text { congestion }\end{array}$ & $6(100) / 0(0)$ & $\mathrm{I}(16.7) / 5(83.3)^{*}$ & $\begin{array}{c}X^{2}=10.894 \\
0.015\end{array}$ \\
\hline $\begin{array}{l}\text { Distortion in the } \\
\text { epididymal gland }\end{array}$ & $6(100) / 0(0)$ & $\mathrm{I}(16.7) / 5(83.3)^{*}$ & $\begin{array}{c}X^{2}=10.894 \\
0.015\end{array}$ \\
\hline $\begin{array}{l}\text { Ductus deferens } \\
\text { dejeneration }\end{array}$ & $6(100)$ & $6(100)$ & - \\
\hline
\end{tabular}

Note: ${ }^{p} \mathrm{p}<0.05$ : compared to group $\mathrm{S}$.

Table 2 The Diameter of Testicular Seminiferous Tubules [Mean \pm SEM]

\begin{tabular}{|l|c|c|c|}
\hline & $\begin{array}{c}\text { Group S } \\
(\mathbf{n}=\mathbf{6})\end{array}$ & $\begin{array}{c}\text { Group K } \\
(\mathbf{n}=\mathbf{6})\end{array}$ & $\mathbf{P}$ \\
\hline Tubule diameter $(\mathrm{mm})$ & $0.194 \pm 0.007$ & $0.215 \pm 0.005^{*}$ & 0.026 \\
\hline
\end{tabular}

Note: ${ }^{*}<0.05$ : compared to group $S$.

group ( $\mathrm{p}=0.026)$ (Table 2) (Figure 2). In staining with $H \& E \times 100$, congested vascular structures were observed in the testicular tissue in the ketamine group (Figure 3). Johnsen scores of the saline and ketamine groups were given in Table 4. Johnsen scores were found to be significantly lower in the ketamine group compared to the saline group $(p=0.013)$. The mean seminiferous tubule containing spermatozoa was found to be significantly lower in the ketamine group compared to the saline group $(\mathrm{p}=0.001)$. However, the mean of seminiferous tubules without spermatozoa was found to be significantly higher in the ketamine group compared to the saline group $(p<0.0001)$. While maturation was observed until the stage of spermatitis, a loss was observed in the formation of spermatozoa in the subsequent spermiogenesis. Loss of maturation was detected in the ketamine group (Table 3).

Vascular congestion were significantly increased in the ketamine group in kidney tissue $(\mathrm{p}=0.049)$ (Table 4), (Figures 4 and 5).

\section{Biochemical Results}

TBARS level was found to be significantly higher in the ketamine group compared to the saline group in the 


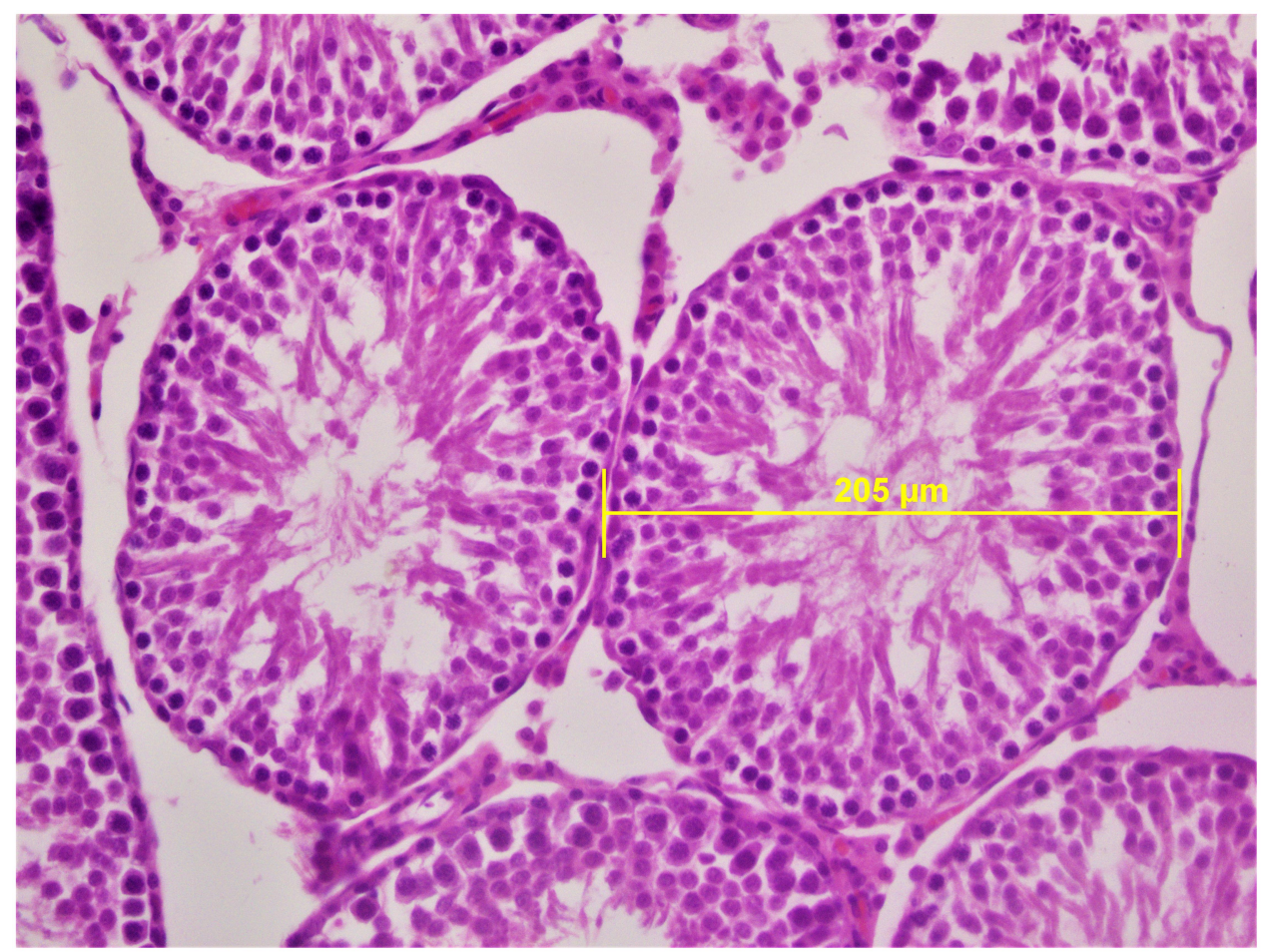

Figure 2 In ketamine group spermatozoa were not observed, only spermatids were seen in the seminiferous tubules. Seminiferous tubule diameters were measured in transverse tubules (H\&E×400).

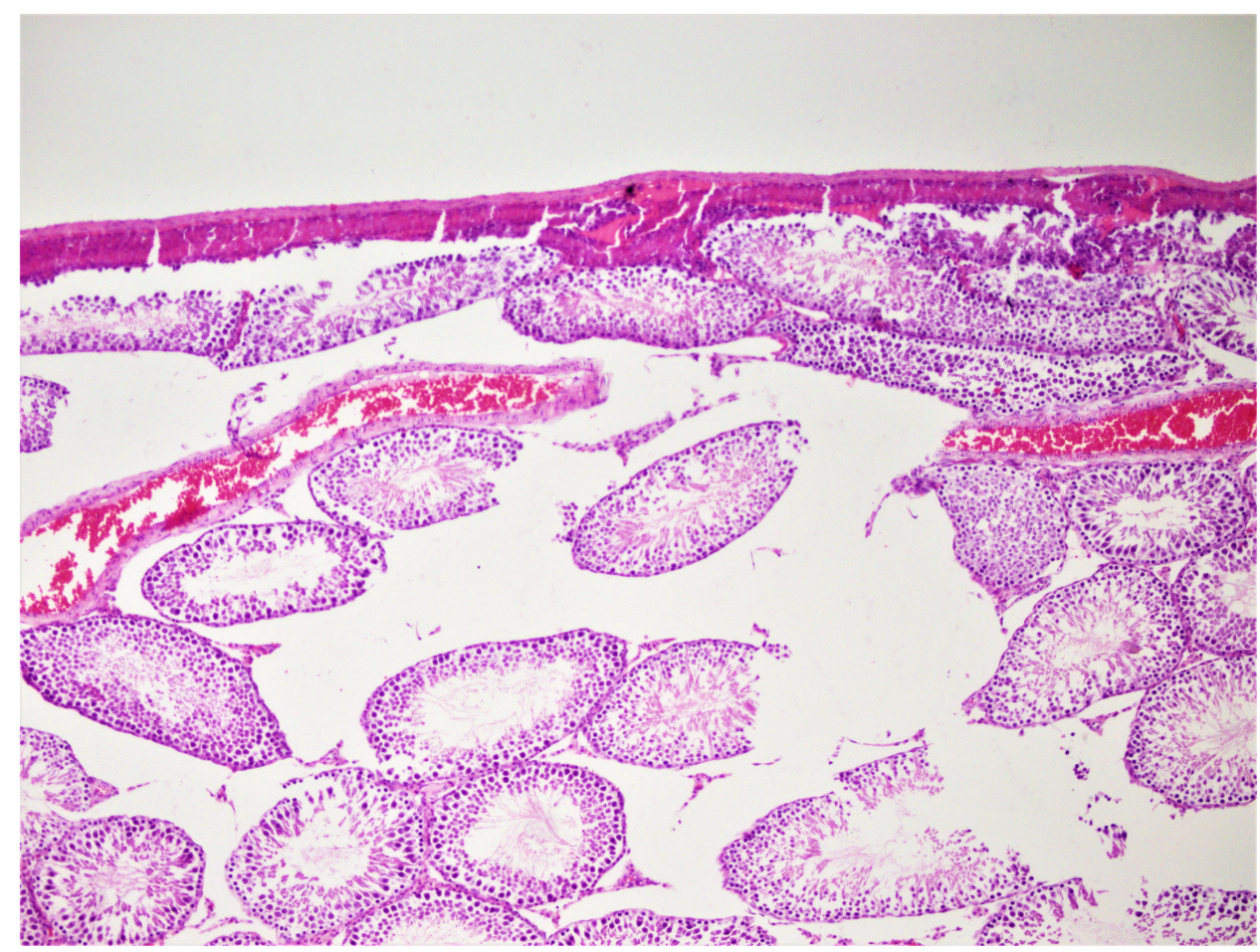

Figure 3 Congestion was observed in the vessels between the seminiferous tubules in the ketamine group $(H \& E \times 100)$.

testicular and kidney tissue $(\mathrm{p}=0.027, \mathrm{p}=0.025$, respectively) (Tables 5 and 6). CAT enzyme activity was found to be significantly lower in the ketamine group in both tissues ( $\mathrm{p}=0.017, \mathrm{p}=0.025$, respectively) (Tables 5 and 6). PON-1 enzyme activity was found to be significantly higher in the ketamine group compared 
Table 3 Johnsen Score Spermatogenesis in the Seminiferous Tubules [Mean \pm SEM]

\begin{tabular}{|l|c|c|c|}
\hline & $\begin{array}{c}\text { Group S } \\
(\mathbf{n = 6})\end{array}$ & $\begin{array}{c}\text { Group K } \\
(\mathbf{n = 6})\end{array}$ & $\mathbf{P}$ \\
\hline Scores & $8.61 \pm 0.12$ & $8.15 \pm 0.10^{*}$ & 0.013 \\
\hline Group 1\& & $5.95 \pm 0.27$ & $4.24 \pm 0.25^{*}$ & 0.001 \\
\hline Group 2 $^{\&}$ & $2.66 \pm 0.16$ & $3.91 \pm 0.16^{*}$ & $<0.0001$ \\
\hline
\end{tabular}

Notes: ${ }^{8}$ Group 1: 8-10 Johnsen score that spermatozoa seen; ${ }^{*}$ group 2: 1-7 Johnsen score that spermatozoa not seen; ${ }^{*} \mathrm{p}<0.05$ : compared to group $\mathrm{S}$.

Table 4 Histopathological Data of Rat Kidney Tissue [Mean \pm SEM]

\begin{tabular}{|l|c|c|c|}
\hline & $\begin{array}{c}\text { Group S } \\
(\mathbf{n}=6)\end{array}$ & $\begin{array}{c}\text { Group K } \\
(\mathbf{n = 6})\end{array}$ & $\mathbf{P}$ \\
\hline Tubular epithelial degeneration & $0.00 \pm 0.00$ & $0.00 \pm 0.00$ & - \\
\hline Tubular epithelial edema & $0.00 \pm 0.00$ & $0.00 \pm 0.00$ & - \\
\hline Vascular congestion & $0.33 \pm 0.21$ & $1.17 \pm 0.3 I^{*}$ & 0.049 \\
\hline Tubule dilation & $0.00 \pm 0.00$ & $0.00 \pm 0.00$ & - \\
\hline Interstitial edema & $0.00 \pm 0.00$ & $0.00 \pm 0.00$ & - \\
\hline Interstitial fibrosis & $0.00 \pm 0.00$ & $0.00 \pm 0.00$ & - \\
\hline Interstitial inflammation & $0.00 \pm 0.00$ & $0.00 \pm 0.00$ & - \\
\hline Glomerular sclerosis & $0.00 \pm 0.00$ & $0.00 \pm 0.00$ & - \\
\hline Bowman capsule fibrosis & $0.00 \pm 0.00$ & $0.00 \pm 0.00$ & - \\
\hline Tubular atrophy & $0.00 \pm 0.00$ & $0.00 \pm 0.00$ & - \\
\hline
\end{tabular}

Note: $* p<0.05$ : compared to group $S$.

to the saline group $(\mathrm{p}=0.049, \mathrm{p}=0.012$, respectively) (Tables 5 and 6).

\section{Discussion}

Because of the low incidence of cardiovascular depression, ketamine is considered a safe drug, especially for children. Ketamine is the most preferred agent by anesthesiologists, especially in procedures such as angiography, endoscopy, bronchoscopy, and radiotherapy. ${ }^{24-27}$

In recent years, the widespread use of ketamine in pediatric anesthesia, especially in repeated applications, has brought many negative effects on metabolism. Ketamine-induced neuroapoptosis has been extensively studied in mice, rats, and rhesus monkeys. Ikonomidou et al administered ketamine to infant rats at equal intervals for 9 hours and stated that this caused a strong apoptotic neurodegeneration pattern in the brain. Neurotoxicity was

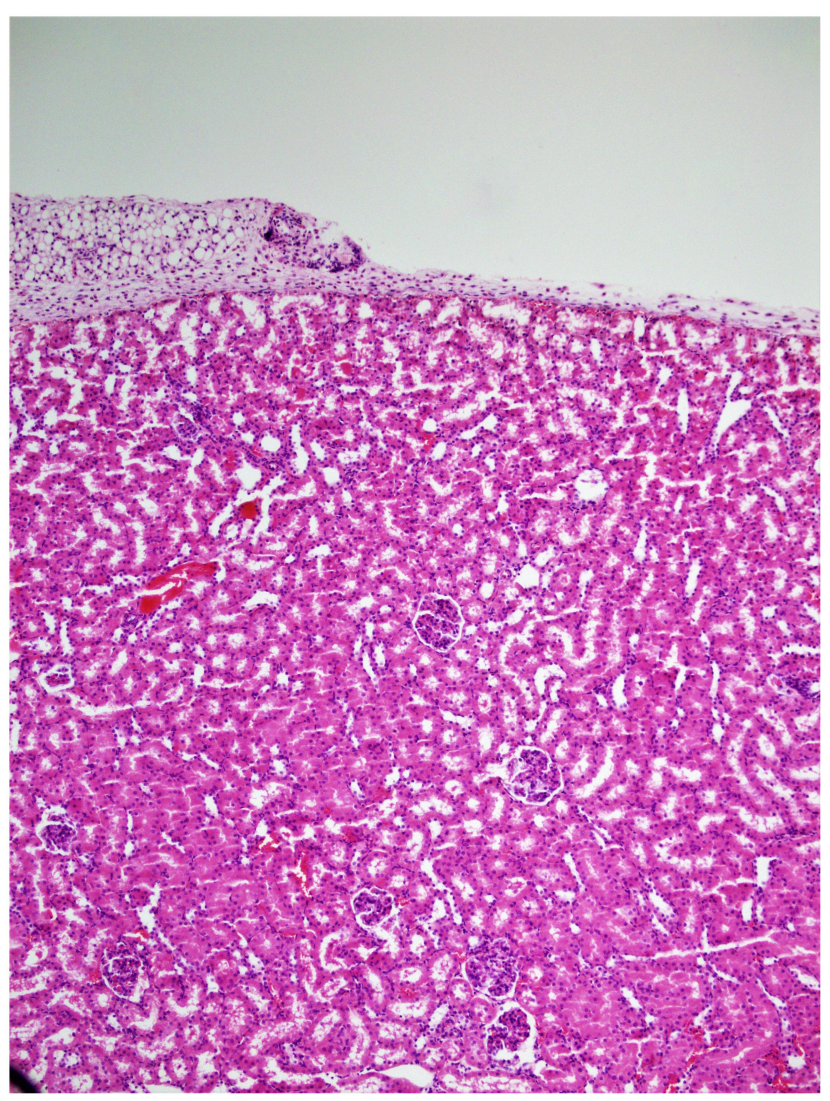

Figure 4 Congested vascular structures were observed focal in the saline group $(\mathrm{H} \& \mathrm{E} \times \mid 00)$

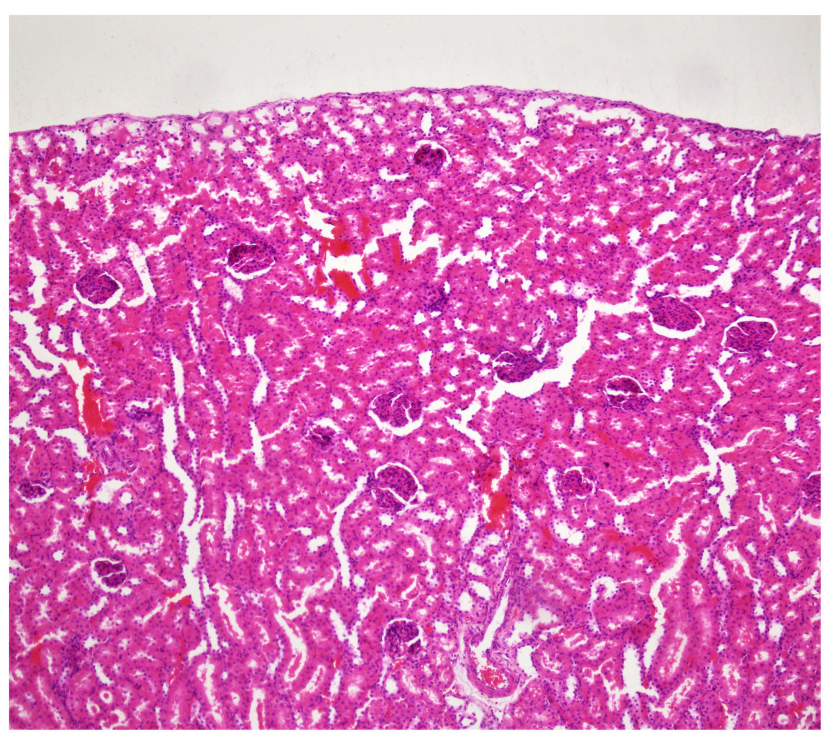

Figure 5 Congested vascular structures were more common in the ketamine group (H\&Ex| 100).

observed when ketamine was administered to 7-day-old rats at a dose of $20-25 \mathrm{mg} / \mathrm{kg} 7$ times every 90 minutes. $^{28,29}$ Signs of neurotoxicity were seen only in the long-term exposed group. Decreased learning, motivation, color 
Table 5 TBARS Level and CAT, PON-I Enzyme Activities of Rat Kidney Tissues [Mean \pm SEM]

\begin{tabular}{|l|c|c|c|}
\hline & $\begin{array}{c}\text { Group S } \\
(\mathbf{n}=6)\end{array}$ & $\begin{array}{c}\text { Group K } \\
(\mathbf{n}=\mathbf{6})\end{array}$ & $\mathbf{P}$ \\
\hline TBARS (nmol/mg protein) & $0.41 \pm 0.02$ & $0.58 \pm 0.06^{*}$ & 0.027 \\
\hline CAT (IU/mg protein) & $1974.00 \pm 48.62$ & $1816.67 \pm 25.70^{*}$ & 0.017 \\
\hline PON-I (IU/mg protein) & $120.87 \pm 23.44$ & $257.58 \pm 61.49^{*}$ & 0.049 \\
\hline
\end{tabular}

Note: $* p<0.05$ : compared to group $S$.

Table 6 TBARS Level and CAT, PON-I Enzyme Activities of Rat Testicular Tissues [Mean \pm SEM]

\begin{tabular}{|l|c|c|c|}
\hline & $\begin{array}{c}\text { Group S } \\
(\mathbf{n}=\mathbf{6})\end{array}$ & $\begin{array}{c}\text { Group K } \\
(\mathbf{n}=\mathbf{6})\end{array}$ & $\mathbf{P}$ \\
\hline TBARS (nmol/mg protein) & $0.32 \pm 0.01$ & $0.46 \pm 0.05^{*}$ & 0.025 \\
\hline CAT (IU/mg protein) & $299.00 \pm 19.99$ & $236.83 \pm 12.64^{*}$ & 0.029 \\
\hline PON-I (IU/mg protein) & $98.57 \pm 20.57$ & $181.30 \pm 17.59 *$ & 0.012 \\
\hline
\end{tabular}

Note: $* \mathrm{p}<0.05$ : compared to group $\mathrm{S}$.

discrimination and short-term memory were observed in subjects taken ketamine for 24 hours. ${ }^{30}$ These findings confirmed that ketamine-induced neurotoxicity was both dose and time dependent. The dose of ketamine used in these studies is about 10 times the amount required to anesthetize humans, and also almost 10 times the therapeutic levels of ketamine. ${ }^{31}$ It is thought that sensitivity to anesthesia-induced neurotoxicity in children covers the period between the last three months of pregnancy and the age of 3 years. ${ }^{32}$ Studies have shown that ketamine and its metabolites in urine lead to a chronic inflammatory response with a direct toxic effect on the bladder urothelium and subsequently to symptoms similar to interstitial cystitis. ${ }^{33}$ In an in vitro study in animal bladder, ketamine has been shown to induce cytotoxicity and increase barrier permeability in these cells in a dose and time dependent manner. Long-term abuse of ketamine has been characterized in all studies that cause ketamine-associated cystitis, and based on this, experimental animal studies have been conducted. Shen et al administered high-dose daily ketamine injections to mice for 20 weeks to demonstrate the effects of long-term ketamine abuse on the bladder. In particular, it has been shown that male mice injected with ketamine were adversely affected. ${ }^{34}$ Di Gu et al showed that ketamine disrupts the proliferation of bladder epithelial cells and causes cystitis by causing defects in the bladder epithelial barrier. ${ }^{35}$ It has been stated that long-term ketamine treatment may affect the sperm environment, causing a decrease in sperm motility that may affect fertility, and this may impair male reproductive function. ${ }^{8}$ In a similar study, Paolıs et al administered $50 \mathrm{mg} / \mathrm{kg}$ ketamine to adult rats for 6 weeks. In conclusion, it was shown that ketamine administration caused a significant decrease in seminiferous tubule diameter, lumen diameter and epithelial height. Significant deterioration was observed in sperm parameters (number, motility, etc.) of rats receiving ketamine. It has also been shown that chronic ketamine administration causes a significant increase in MDA levels. ${ }^{18}$ Soltani et al investigated the effect of hydroalcoholic extract of Matricaria chamomile (MC) on torsion/detorsion (T/D) injury. ${ }^{20}$ In this study, they applied only T/D to the control group and applied MC treatment before T/D to the study group. They showed that the levels of antioxidant enzymes superoxide dismutase, glutathione peroxidase and testosterone decreased in the control group but increased in the MC group. Increased MDA levels during ischemia have also been shown to decrease with MC treatment. In the same study, the average Johnson score was found to be lower in the T/D and T/D + MC groups compared to the control group. It was observed that the $\mathrm{MC}$ and control groups did not differ significantly in terms of the mean Johnson score, and the seminiferous tubule diameter was significantly reduced in the T/D group compared to the control group. It was observed that the diameter of the seminiferous tubule increased significantly in the group receiving $\mathrm{MC}$ extract compared to the T/D group. ${ }^{20}$ Similar effects were seen in verapamil/tadalafil combination therapy. ${ }^{21}$ Shoorei et al demonstrated that oral administration of Fumaria parviflora (FP) 14 days before detorsion in adult male rats significantly decreased the apoptosis index, bax gene expression and MDA levels. ${ }^{36}$ In another study with onion juice, it was shown that the use of onion juice after testicular T/D can increase sperm quality and fertility. ${ }^{37}$ Our study was conducted on infants who took ketamine for a shorter period of 3 weeks and oxidative stress parameters in metabolism were measured. It was determined that TBARS level, which is an indicator of oxidative stress significantly increased, and antioxidant CAT enzyme activity significantly decreased in the ketamine group in testicular and kidney tissues. In rat testicular tissue treated with Syzygium aromaticum extract, Johnson's score, seminiferous tubule diameter, and seminiferous tubule epithelial thickness were shown to increase significantly compared to the untreated group. ${ }^{21}$

In this study we observed that vascular congestion in the kidney significantly increased in the ketamine group 
compared to the saline group. We also found vascular congestion in the testicle and distortion in the epididymal glands. Johnsen scores were found to be significantly lower in the ketamine group compared to the saline group. The mean of seminiferous tubules containing spermatozoa was significantly lower in the ketamine group than in the control group. Maturation was observed in the ketamine group until the stage of spermatitis, while loss in spermiogenesis was observed in the formation of spermatozoa. Loss of maturation was detected in the ketamine group. In the ketamine group, vascular congestion in the testicle and distortion in the glands may have led to nutritional disorders and loss of maturation in spermatogenesis. The time to onset of clinical symptoms after ketamine abuse can range from a few days to a few years. In our study, ketamine was administered to infant rats during 21 days to characterize the effects on the urogenital system and to examine the critical changes in infants who were sedated with ketamine for an average of 21 days for radiotherapy. In the literature, we did not find any other study about ketamine based on the pediatric age group for long-term sedation. Compared to other studies, ketamine administration was applied for a short time. Nevertheless, we observed that repeated ketamine administration caused significant histological changes and oxidative damage in epididymis, testicular and kidney tissues.

There are 2 limitations in our study. First one is low number of animals used in groups, second is power analysis was not performed in the study.

We concluded that the results we obtained will be a guide for repeatedly administered ketamine in daily anesthesia practice, especially in the pediatric age group.

\section{Disclosure}

The authors report no conflicts of interest for this work.

\section{References}

1. Marland S, Ellerton J, Andolfatto G, et al. Ketamine: use in anesthesia. CNS Neurosci Ther. 2013;19(6):381-389. doi:10.1111/cns.12072

2. Dong TT, Mellin-Olsen J, Gelb AW. Ketamine: a growing global health-care need. Br J Anaesth. 2015;115:491-493. doi:10.1093/bja/ aev215

3. Kurdi MS, Theerth KA, Deva RS. Ketamine: current applications in anesthesia, pain, and critical care. Anesth Essays Res. 2014;8(3):283290. doi:10.4103/0259-1162.143110

4. Karacaer F, Biricik E, Ilgınel M, et al. Remifentanil-ketamine vs. propofol-ketamine for sedation in pediatric patients undergoing colonoscopy: a randomized clinical trial. Rev Bras Anestesiol. 2018;68 (6):597-604.
5. Gulec H, Sahin S, Ozayar E, et al. Ketamine-propofol sedation in circumcision. Braz J Anesthesiol. 2015;65(5):367-370. doi:10.1016/j. bjan.2014.03.002

6. Kim KM, Lee KH, Kim YH, et al. Comparison of effects of intravenous midazolam and ketamine on emergence agitation in children: randomized controlled trial. $J$ Int Med Res. 2016;44(2):258-266. doi: $10.1177 / 0300060515621639$

7. Stoelting RK, Hillier SC. Nonbarbiturate intravenous anaesthetic drugs. In: Stoelting RK, Hillier SC, editors. Pharmacology and Physiology in Anaesthetic Practice. 4th ed. Philadelphia: Lippincott Williams and Wilkin; 2006:155-178.

8. Absalan F, Ghannadi A, Zabihi A. The effects of different doses of ketamine on quality of normal ejaculated sperm. Int J Fertil Steril. 2014;8(2):207-214.

9. Tsai TH, Cha TL, Lin CM, et al. Ketamine-associated bladder dysfunction. Int $J$ Urol. 2009;16(10):826-829. doi:10.1111/j.14422042.2009.02361.x

10. Lee P, Ong T, Chua C, et al. Street ketamine-associated bladder dysfunction: an emerging health problem. Malays Fam Physician. 2009;4(1):15-18.

11. Wei YB, Yang JR, Yin Z, et al. Genitourinary toxicity of ketamine. Hong Kong Med J. 2013;19(4):341-348. doi:10.12809/hkmj134013

12. Shen $\mathrm{CH}$, Wang SC, Wang ST, et al. Evaluation of urinary bladder fibrogenesis in a mouse model of long-term ketamine injection. Mol Med Rep. 2016;14(3):1880-1890. doi:10.3892/mmr.2016.5482

13. Rudin M, Ben-Abraham R, Gazit V, et al. Single-dose ketamine administration induces apoptosis in neonatal mouse brain. J Basic Clin Physiol Pharmacol. 2005;16(4):231-243. doi:10.1515/JBCPP.2005.16.4.231

14. Chopineau J, Sommier MF, Sautou V. Evaluation of free radical production in an ischaemia-reperfusion model in the rabbit using a tourniquet. J Pharm Pharmacol. 1994;46(6):519-520. doi:10.1111/ j.2042-7158.1994.tb03842.x

15. Halliwell B. Reactive oxygen species in living systems: source, biochemistry, and role in human disease. Am J Med. 1991;91 (3C):14S-22S. doi:10.1016/0002-9343(91)90279-7

16. Kuroda S, Yumura Y, Mori K, et al. Negative correlation between presence of reactive oxygen species and sperm motility Index in whole semen samples of infertile males. Rev Int Androl. 2017;15:84-89.

17. Atig F, Kerkeni A, Saad A, et al. Effects of reduced seminal enzymatic antioxidants on sperm DNA fragmentation and semen quality of Tunisian infertile men. J Assist Reprod Genet. 2017;34(3):373381. doi:10.1007/s10815-013-9936-x

18. Paulis MG, Hafez EM, El-Tahawy NF. Toxicity and postwithdrawal effects of ketamine on the reproductive function of male albino rats: hormonal, histological, and immunohistochemical study. Hum Exp Toxicol. 2020;39(8):1054-1065. doi:10.1177/0960327120909857

19. Ighodaro OM, Akinloye OA. First line defence antioxidants-superoxide dismutase (SOD), catalase (CAT) and glutathione peroxidase (GPX): their fundamental role in the entire antioxidant defence grid. Alex J Med. 2018;54:287-293. doi:10.1016/j.ajme.2017.09.001

20. Soltani M, Moghimian M, Abtahi-Eivari SH, et al. Protective effects of matricaria chamomilla extract on torsion/detorsion-induced tissue damage and oxidative stress in adult rat testis. Int J Fertil Steril. 2018;12(3):242-248. doi:10.22074/ijfs.2018.5324

21. Moghimian M, Abtahi-Evari SH, Shokoohi M, Amiri M, Soltani M. Effect of Syzygium aromaticum (clove) extract on seminiferous tubules and oxidative stress after testicular torsion in adult rats. Physiol Pharmacol. 2017;21(4):343-350.

22. Turner TT, Lysiak JJ, Shannon JD, Nguyen QA, Bazemore-Walker CR. Testicular torsion alters the presence of specific proteins in the mouse testis as well as the phosphorylation status of specific proteins. $J$ Androl. 2006;27(2):285-293. doi:10.2164/jandrol.05134

23. Johnsen SG. Testicular biopsy score count-a method for registration of spermatogenesis in human testes: normal values and results in 335 hypogonadal males. Hormones. 1970;1(1):2-25. doi:10.1159/00017 8170 
24. Morris C, Perris A, Klein J, Mahoney P. Anaesthesia in haemodynamically compromised emergency patients: does ketamine represent the best choice of induction agent? Anaesthesia. 2009;64(5):532-539. doi:10.1111/j.1365-2044.2008.05835.x

25. Gyanesh P, Haldar R, Srivastava D, Agrawal PM, Tiwari AK, Singh PK. Comparison between intranasal dexmedetomidine and intranasal ketamine as premedication for procedural sedation in children undergoing MRI: a double-blind, randomized, placebo-controlled trial. $J$ Anesth. 2014;28(1):12-18. doi:10.1007/s00540-013-1657-x

26. Khutia SK, Mandal MC, Das S, Basu SR. Intravenous infusion of ketamine-propofol can be an alternative to intravenous infusion of fentanyl-propofol for deep sedation and analgesia in paediatric patients undergoing emergency short surgical procedures. Indian $J$ Anaesth. 2012;56:145-150. doi:10.4103/0019-5049.96313

27. Law $\mathrm{AK}, \mathrm{Ng} \mathrm{DK}$, Chan $\mathrm{KK}$. Use of intramuscular ketamine for endoscopy sedation in children. Pediatr Int. 2003;45(2):180-185. doi:10.1046/j.1442-200X.2003.01680.x

28. Ikonomidou C, Bosch F, Miksa M, et al. Blockade of NMDA receptors and apoptotic neurodegeneration in the developing brain. Science. 1999;283(5398):70-74. doi:10.1126/science.283.5398.70

29. Hayashi H, Dikkes P, Soriano SG. Repeated administration of ketamine may lead to neuronal degeneration in the developing rat brain Paediatr Anaesth. 2002;12(9):770-774. doi:10.1046/j.1460-9592.20 02.00883.x

30. Paule MG, Li M, Allen RR, et al. Ketamine anesthesia during the first week of life can cause long-lasting cognitive deficits in rhesus monkeys. Neurotoxicol Teratol. 2011;33(2):220-230. doi:10.1016/j.ntt.20 11.01 .001
31. Slikker W Jr, Zou X, Hotchkiss CE, et al. Ketamine-induced neuronal cell death in the perinatal rhesus monkey. Toxicol Sci. 2007;98 (1):145-158. doi:10.1093/toxsci/kfm084

32. Dobbing J, Sands J. Comparative aspects of the brain growth spurt. Early Hum Dev. 1979;3(1):79-83. doi:10.1016/0378-3782 (79)90022-7

33. Tsai YC, Kuo HC. Ketamine cystitis: its urological impact and management. Urol Sci. 2015;26(3):153-157. doi:10.1016/j.urols.20 14.11.003

34. Shen CH, Wang ST, Lee YR, et al. Biological effect of ketamine in urothelial cell lines and global gene expression analysis in the bladders of ketamine-injected mice. Mol Med Rep. 2015;11(2):887-895. doi:10.3892/mmr.2014.2823

35. Gu D, Huang J, Yin Y, Shan Z, Zheng S, Wu P. Long-term ketamine abuse induces cystitis in rats by impairing the bladder epithelial barrier. Mol Biol Rep. 2014;41(11):7313-7322. doi:10.1007/s11033014-3616-5

36. Shokoohi M, Shoorei H, Soltani M, Abtahi-Eivari SH, Salimnejad R, Moghimian M. Protective effects of the hydroalcoholic extract of Fumaria parviflora on testicular injury induced by torsion/detorsion in adult rats. Andrologia. 2018;50(7):e13047. doi:10.1111/and.13047

37. Shokoohi M, Madarek EOS, Khaki A, et al. Investigating the effects of onion juice on male fertility factors and pregnancy rate after testicular torsion/detorsion by intrauterine insemination method. Int $J$ Womens Health Reprod Sci. 2018;6:499-505. doi:10.15296/ijwhr. 2018.82
Drug Design, Development and Therapy

\section{Publish your work in this journal}

Drug Design, Development and Therapy is an international, peerreviewed open-access journal that spans the spectrum of drug design and development through to clinical applications. Clinical outcomes, patient safety, and programs for the development and effective, safe, and sustained use of medicines are a feature of the journal, which has also

\section{Dovepress}

been accepted for indexing on PubMed Central. The manuscript management system is completely online and includes a very quick and fair peer-review system, which is all easy to use. Visit http://www. dovepress.com/testimonials.php to read real quotes from published authors. 